\title{
Separation on Urografin Gradients of Subpopulations from Sporulating Saccharomyces cerevisiae Cultures
}

\author{
By IAN W. DAWES, * JOHN F. WRIGHT, FRANCOISE VEZINHET $\dagger$ \\ AND NONI AJAM \\ Department of Microbiology, University of Edinburgh, Edinburgh EH9 $3 J G$
}

(Received 5 October 1979; revised 7 February 1980)

\begin{abstract}
Sporulating yeast populations were separated into a number of fractions by centrifugation through linear density gradients of Urografin. At least eight distinct fractions could be obtained from cultures that were just beginning to produce asci visible by phase contrast microscopy. Cells in these fractions were found to differ in the stage they had reached in meiosis and sporulation; those more advanced in sporulation banded at a lower density. Using this gradient centrifugation method it was shown that cultures induced to sporulate by the usual technique were markedly heterogeneous with respect to the stage in meiosis and sporulation reached by the cells, and that most of the labelled amino acids incorporated into protein by sporulating cultures appeared in those cells not yet committed to either recombination or meiosis.
\end{abstract}

\section{INTRODUCTION}

Saccharomyces cerevisiae provides a system in which meiosis and the subsequent developmental system of ascospore formation are amenable to biochemical and genetic analysis. For most purposes the processes can be induced in an adequate proportion of cells in a culture (usually between 70 and $80 \%$ ) with a reasonable degree of synchrony by using the resuspension techniques of either Roth \& Halvorson (1969) or Fast (1973). There are, however, situations in which asynchrony and the presence of non-sporulating cells in such cultures can distort the results obtained; this is particularly so when sequential changes are under study and pulse-labelling techniques are in use. A procedure has been described that is based on sporulation of cultures synchronized with respect to cell division (Sando et al., 1973), but this is still subject to the problem of incomplete induction of sporulation in the population.

Here we describe a technique that resolves sporulating populations into fractions conaining cells at different stages of the processes of meiosis and sporulation. Using this method we have been able to illustrate the heterogeneity of cultures induced to sporulate according to the procedure of Fast (1973) and to show marked differences between cells in the various fractions with respect to the incorporation of labelled amino acids. These results highlight the problems associated with pulse-labelling studies since most of the label incorporated into a $16 \mathrm{~h}$ sporulation culture containing $1 \%$ asci was found in cells which had not even become committed to meiosis.

$\dagger$ Present address: Laboratoire de Technologie végétale, Institut National de la Recherche Agronomique, Ecole Nationale Supérieure Agronomique, 34060 Montpellier Cedex, France. 


\section{METHODS}

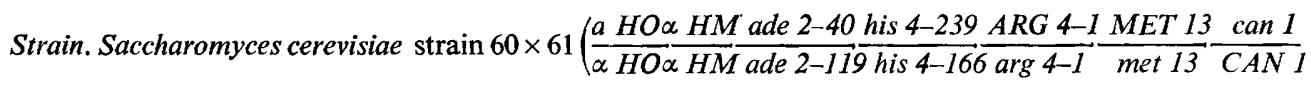
$\frac{C Y H 2}{c y h 2}$ )was constructed from a variety of strains including some supplied by Dr F. Zimmerman, Darmstadt, F.R.G., and the Yeast Genetics Stock Culture Collection, Berkeley, U.S.A. The ade 2-40 and ade 2-119 alleles complement and the parent diploid is adenine-independent with white colonies. However, once meiosis and segregation of the nuclei has occurred, the haploid progeny require adenine and give colonies that are either red (ade 2-40) or pink (ade 2-119, a leaky mutation). This means that cells committed to completing meiosis can be scored directly after plating on any medium. Cells committed to recombination can be scored by testing for loss of the histidine requirement due to recombination between the non-complementing alleles of the his 4 gene complex. $H O \alpha$ and $H M$ are genes concerned with homothallism. The genes can 1 and cyh 2 confer recessive resistances to $\mathrm{L}$-canavanine sulphate $\left(80 \mu \mathrm{g} \mathrm{ml}^{-1}\right)$ and to cycloheximide $\left(5 \mu \mathrm{g} \mathrm{ml}^{-1}\right)$, respectively; these genes are both present in the heterozygous state and the appearances of resistant organisms can also be used as marker events during sporulation. The strain was maintained on YEPD agar $\left[1 \%(\mathrm{w} / \mathrm{v})\right.$ yeast extract, $2 \%(\mathrm{w} / \mathrm{v})$ peptone, $2 \%(\mathrm{w} / \mathrm{v})$ glucose, $2 \%(\mathrm{w} / \mathrm{v})$ agar] at $0{ }^{\circ} \mathrm{C}$, and was cloned before use.

Sporulation. Cultures were grown to a turbidity of $1(600 \mathrm{~nm})$ on YPA medium $[1 \%(\mathrm{w} / \mathrm{v})$ yeast extract, $2 \%(\mathrm{w} / \mathrm{v})$ peptone, $2 \%(\mathrm{w} / \mathrm{v})$ potassium acetate] and were induced to sporulate, according to the method of Fast (1973), by resuspension in $2 \%(\mathrm{w} / \mathrm{v})$ potassium acetate, $\mathrm{pH} 5.5$, supplemented with the appropriate auxotrophic requirements.

Incidence of asci and buds. The percentage of asci in each fraction was determined by direct counting using phase contrast microscopy. There is in this method an element of subjective judgement since the developing ascospores can be discerned before they appear as distinct and separate entities. This was most noticeable in scoring fractions since different fractions contained different stages in the development of the ascus. Buds were counted as separate cells, and, where possible, sporulating cultures with a low proportion of budded cells were used.

Uptake and incorporation of labelled amino acids. Separate uptake and incorporation studies were done using either $\mathrm{L}_{-}\left[{ }^{14} \mathrm{C}\right]$ phenylalanine or $\mathrm{L}-\left[{ }^{14} \mathrm{C}\right]$ arginine. The sporulating culture $(3 \mathrm{ml})$ was either labelled directly by adding the labelled amino acid as described below, or it was first centrifuged at $3000 \mathrm{~g}$ for $2 \mathrm{~min}$ and the cell pellet was resuspended in the same volume of either $2 \%(\mathrm{w} / \mathrm{v})$ potassium acetate adjusted to $\mathrm{pH} 6$, or $2 \%(\mathrm{w} / \mathrm{v})$ potassium acetate buffered to $\mathrm{pH} 6$ with $0.2 \mathrm{M}$-morpholinopropanesulphonic acid (MOPS). The resuspension medium was warmed to $30^{\circ} \mathrm{C}$ before use, and contained $\mathrm{L}-\left[{ }^{14} \mathrm{C}\right]$ arginine at $5 \mu \mathrm{Ci}$ $\mathrm{ml}^{-1}\left(185 \mathrm{kBq} \mathrm{ml}^{-1}\right)$ and $5 \mu \mathrm{g} \mathrm{ml}^{-1}$, or $\mathrm{L}^{-}\left[{ }^{14} \mathrm{C}\right]$ phenylalanine at $5 \mu \mathrm{Ci} \mathrm{ml}^{-1}\left(185 \mathrm{kBq} \mathrm{ml}^{-1}\right)$ and $5 \mu \mathrm{g} \mathrm{ml}^{-1}$. After a pulse of $10 \mathrm{~min}$, a sample $(1 \mathrm{ml})$ was gently layered over the Urografin (Schering Chemicals Ltd, Burgess Hill, West Sussex) gradient and centrifuged immediately (see below). Under these conditions uptake refers to the amount of ${ }^{14} \mathrm{C}$ retained by the cells after centrifugation through the Urografin gradient. Samples $(10 \mu \mathrm{l})$ from each fraction obtained from the gradient were transferred directly into scintillant (1 ml Insta-Gel, Packard Instrument Co.) and counted.

Incorporation into trichloroacetic acid (TCA)-precipitable material was measured by taking $0 \cdot 1 \mathrm{ml}$ samples from each fraction into $10 \%(\mathrm{w} / \mathrm{v}) \mathrm{TCA}$ at $0{ }^{\circ} \mathrm{C}$ and, after $30 \mathrm{~min}$, filtering on nitrocellulose filters $(0.45 \mu \mathrm{m}$ pore size). The filters were counted in $3 \mathrm{ml}$ of $0.4 \%(\mathrm{w} / \mathrm{v}) 2,5$-diphenyloxazole in toluene.

Density-gradient centrifugation. Linear Urografin density gradients were prepared in $16.5 \mathrm{ml}$ capacity polycarbonate centrifuge tubes (MSE code 0178) over the density range specified, usually within the limits of 1.13 to $1.22 \mathrm{~g} \mathrm{~cm}^{-3}$. Best separations were achieved using a density range of about $0.06 \mathrm{~g} \mathrm{~cm}^{-3}$, and since these were quite shallow gradients, experiments were often carried out using several gradients with different ranges and that yielding the best separation was used for analysis. Samples $(1 \mathrm{ml})$ of sporulating cultures (containing about $10^{8}$ cells) were gently layered on the gradients and the tubes were centrifuged at $4500 \mathrm{~g}$ (max.) for $10 \mathrm{~min}$ in an MSE Super-Minor centrifuge with swing-out rotor. Fractions (0.3 $\mathrm{ml})$ were obtained by piercing the tube and collecting from the bottom of the gradient.

Density estimation. The density of each fraction was determined by measuring its refractive index and comparing this with a standard curve prepared from Urografin solutions of known density.

Cell concentration and viability. Cell concentrations were estimated in terms of the turbidity of samples at $600 \mathrm{~nm}$. Samples were diluted 10- or 20-fold to reduce the effect of refractive index changes due to the presence of Urografin. Cell viability was estimated by plating appropriate dilutions of the fractions on YEPD plates. After incubation of these plates for at least $3 \mathrm{~d}$ at $30{ }^{\circ} \mathrm{C}$ it was possible to score for the red/pink characte displayed by the ade 2 auxotrophs, as well as to estimate the total viable count.

Sectored colonies were presumed to have arisen either by recombination or segregation within an ascus, 


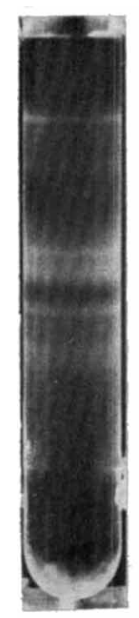

(a)

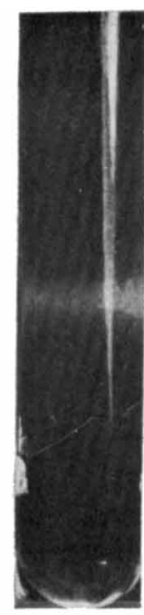

$\mathrm{Oh}$

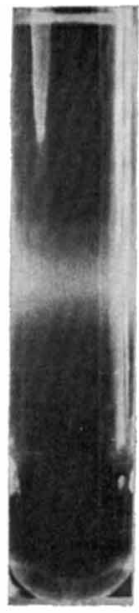

$5 \mathrm{~h}$

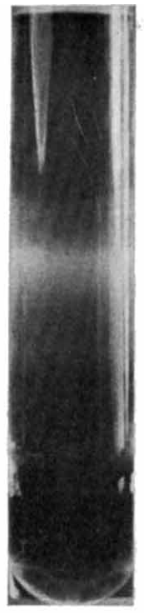

$10 \mathrm{~h}$

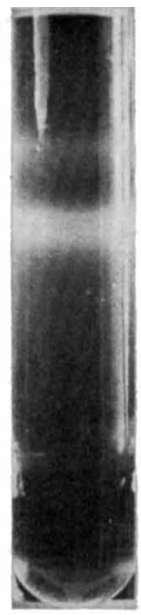

$15 \mathrm{~h}$

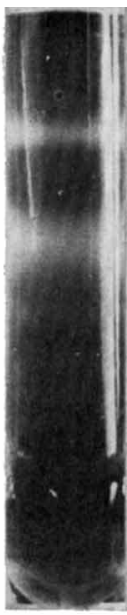

$20 \mathrm{~h}$

(b)

Fig. 1. Separation of sporulating cultures into subpopulations. (a) The pattern of cell banding observed on centrifugation of a $20 \mathrm{~h}$ sporulation culture through a linear gradient of Urografin (centrifugation time, $15 \mathrm{~min}$; density range, 1.13 to $1.20 \mathrm{~g} \mathrm{~cm}^{-3}$ ). (b) The effect of sporulation time: samples taken at the times indicated after resuspension in sporulation medium were separated on Urografin gradients (centrifugation for $15 \mathrm{~min}$; density range, $1 \cdot 13$ to $1.22 \mathrm{~g} \mathrm{~cm}^{-3}$ ).

and were scored as single viable units. Urografin did not appear to affect the viability of cells at any stage of sporulation.

Commitment to recombination. Fractions were diluted appropriately, plated on defined complete medium plates (Dawes et al., 1977) lacking histidine as supplement and the plates were incubated at $30^{\circ} \mathrm{C}$ for at least $5 \mathrm{~d}$. Colonies were counted and the ratio of histidine-independent to total viable units was taken as an indication of the extent of commitment to intragenic recombination (Esposito \& Esposito, 1974).

\section{RESULTS}

\section{Separation of sporulating cultures on Urografin gradients}

Initial experiments using linear Urografin gradients covering various density ranges indicated that sporulating yeast populations could be resolved into a number of bands by centrifugation, whereas under the same conditions vegetative populations were not. Best results (for example Fig. 1 a) were obtained by layering $1 \mathrm{ml}$ of culture over a very shallow gradient (density 1.15 to $1.20 \mathrm{~g} \mathrm{~cm}^{-3}$ ) in long tubes $(97 \mathrm{~mm}, 16.5 \mathrm{ml}$ capacity) and centrifuging at low speed $(4500 \mathrm{~g})$ for 10 to $15 \mathrm{~min}$. These centrifugation times were not long enough for cells to attain their eventual equilibrium position. The changes in cell banding pattern with centrifugation time were found to be complex (some cells even moved to a high density position and then to one of lower density), and the exact procedure for any given yeast strain had to be determined on each occasion.

\section{Resolution of cultures at different times after induction of sporulation}

Figure $1(b)$ shows the changes in the pattern of cell banding when cultures were separated (centrifugation for $15 \mathrm{~min}$ ) at intervals of $5 \mathrm{~h}$ throughout sporulation. Several points were evident from these results. First, the presence of discrete bands in many of the samples indicates that there are distinct physical changes (presumably reflecting different physiological states) undergone by cells placed under sporulation conditions, and that the transition of cells from one state to another is fairly rapid, otherwise the cells would have been distributed much more broadly. Secondly, significant changes occur during sporulation 


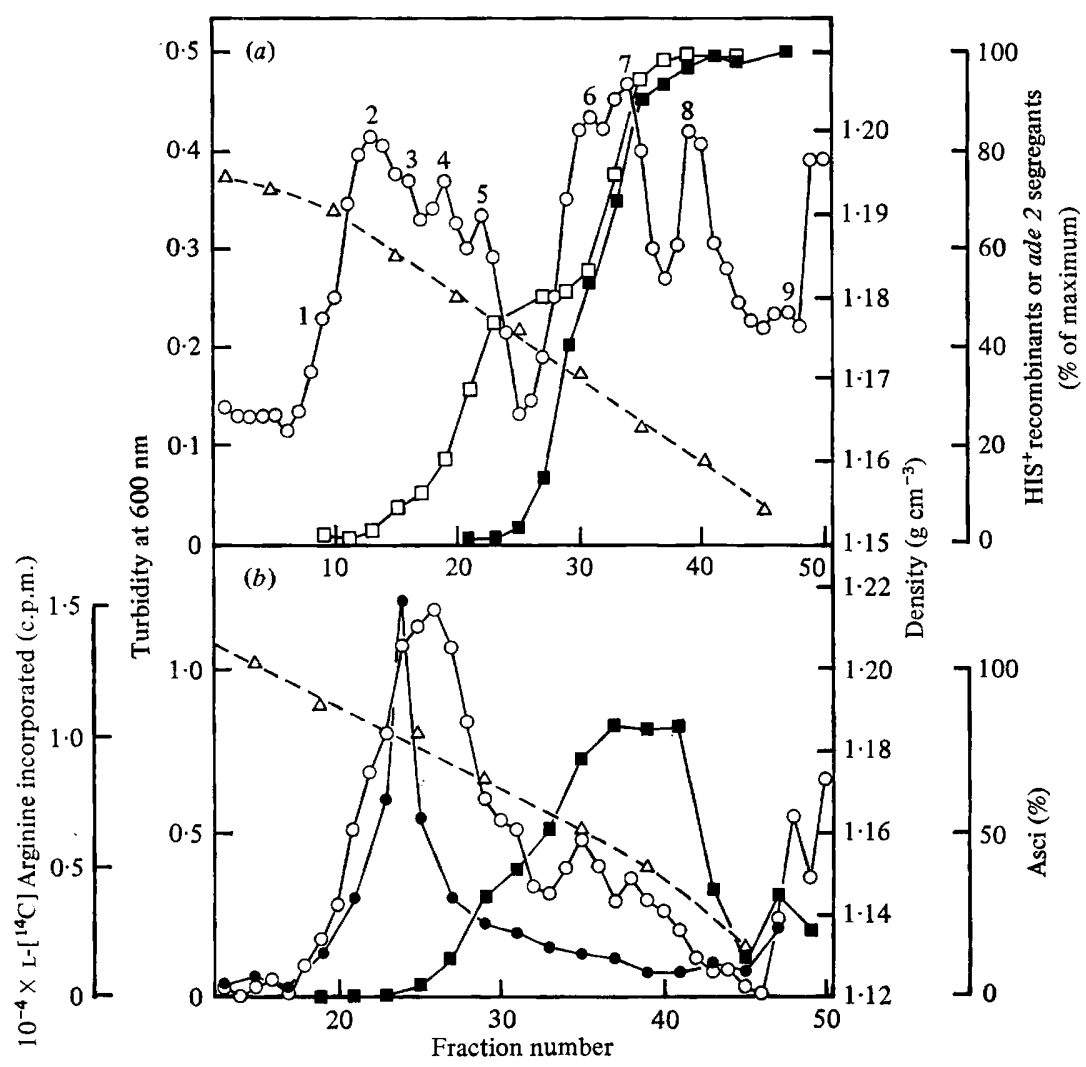

Fig. 2. Heterogeneity of sporulating cultures. (a) A $16.5 \mathrm{~h}$ sporulation culture was separated on a linear gradient $\left(1.15\right.$ to $\left.1.195 \mathrm{~g} \mathrm{~cm}^{-3}\right)$. The tube was pierced, fractions were collected from below and the following were estimated: turbidity at $600 \mathrm{~nm}(0)$; commitment to recombination at the his 4 locus $(\square)$; commitment to meiosis $(\square)$; density of Urografin $(\triangle)$. Results are shown as a percentage of the maximum values for recombination $\left(6.1 \times 10^{3} \mathrm{HIS}^{+} \mathrm{ml}^{-1}\right)$ and meiosis $(35 \%$ red-sectored colonies). Peaks are numbered 1 to 9 . (b) Incorporation of $\mathrm{L}-\left[{ }^{[14} \mathrm{C}\right]$ arginine by subpopulations in a $21 \mathrm{~h}$ sporulation culture. After pulse-labelling with arginine for $10 \mathrm{~min}$ the culture was separated on a linear gradient $\left(1.13\right.$ to $\left.1.20 \mathrm{~g} \mathrm{~cm}^{-3}\right)$. Fractions were collected and assayed for Larginine incorporated into TCA-precipitable material (๑). The following were also estimated: turbidity at $600 \mathrm{~nm}(O)$; percentage of asci $(\boldsymbol{\square})$; density of Urografin $(\triangle)$.

leading to an increased complexity of the banding pattern obtained at later sporulation times. As sporulation proceeded, fractions of apparently lower density appeared; most obvious was the uppermost band seen in Fig. 1(b). Thirdly, there is a marked increase in the heterogeneity of sporulating cultures with time after resuspension under conditions supporting meiosis and sporulation. The different fractions were therefore isolated and analysed to see if they contained cells at different stages of meiosis and sporulation.

\section{Heterogeneity of sporulating cultures}

The different bands obtained on Urografin gradients did contain cells in different stages of meiosis and sporulation. This was shown by separating sporulating cultures, collecting fractions and analysing them for events characteristic of sporulation. These included: commitment to recombination (by scoring for intragenic recombination at the his 4 locus); commitment to meiosis (by segregation of the ade 2 gene); and appearance of recognizable asci. In addition, cell turbidity and density were estimated.

Results are plotted in Fig. 2(a) for a $16.5 \mathrm{~h}$ sporulation culture; the separation achieved 
in this experiment was one of the best obtained using a very shallow gradient. In the strain used, tetrads normally began to appear between 15 and $16 \mathrm{~h}$ after resuspension in sporulation medium, and these reached a maximum of about $70 \%$ of the population at 24 to $30 \mathrm{~h}$. Most $(80 \%)$ of the asci were four-spored under the conditions used. From Fig. 2(a) it can be seen that cells in the lower, denser part of the gradient were uncommitted to either recombination or meiosis, and that only those in the upper bands (numbered 6 to 9) showed any signs of segregation of the ade 2 markers. Histidine-independent recombinants were detected in band 5 as well as in bands 6 to 9 , but the maximum frequency of recombinants was not seen until band 7. Most cells in bands 1 to 5 were unbudded, and no asci were seen on microscopic examination. In band 6 no mature asci were found, but the population contained a high proportion of cells in which the first signs of ascus formation were just evident. Band 7 contained approximately $10 \%$ mature asci; the remaining cells were immature asci similar to those seen in band 6. Band 8 contained more than $60 \%$ asci and cells found above this were almost all mature asci.

It is evident from these results that $16.5 \mathrm{~h}$ after resuspension in sporulation medium about half of the population was not yet committed to meiotic recombination (at the his 4 locus), although some had completed recombination, meiosis and formation of mature ascospores. This indicated that sporulating cultures contained cells that had progressed through meiosis and sporulation to different extents. Clearly, any measurement made on an unresolved sample taken at a particular time from such a population could give a misleading impression of events taking place at a particular stage of sporulation. This was most obvious in studies of the uptake and incorporation of amino acids by sporulating populations.

\section{Uptake and incorporation of labelled amino acids}

Pulse-labelling techniques have considerable use in tracing the fate of metabolites, or in studying the synthesis of particular molecules, but the results of such studies need to be viewed with caution when using heterogeneous populations. In the light of the above results, and the fact that sporulating cultures incorporate precursors of macromolecules at a much lower rate than vegetatively growing ones (Esposito et al., 1970; Mills, 1972; Magee \& Hopper, 1974), the uptake and incorporation of two amino acids, L-phenylalanine and L-arginine, by the different subpopulations in sporulating cultures was examined. In these experiments two methods were used to label the cultures. The first involved the direct addition of the labelled amino acid to a sporulating culture, and after 10 min incubation it was centrifuged through an appropriate Urografin gradient. The second method was that of Mills (1972) in which cells from sporulating cultures were harvested by rapid centrifugation and resuspended in potassium acetate $(0 \cdot 2 \mathrm{M})$ buffered to $\mathrm{pH} 6$ prior to the addition of the labelled amino acid.

The results from both methods were qualitatively similar; those presented here were obtained using potassium acetate at $\mathrm{pH} 6$. Figure $2(b)$ shows the extent to which the different cell types took up and incorporated L- $\left[{ }^{14} \mathrm{C}\right]$ arginine when a $21 \mathrm{~h}$ culture containing $20 \%$ asci was pulse-labelled prior to separation on a Urografin gradient. In this experiment both the total radioactivity taken up and that precipitable by cold $10 \%(\mathrm{w} / \mathrm{v})$ TCA were estimated. The distribution of total activity and of TCA-insoluble activity was similar except at the top of the gradient where unincorporated label remained during centrifugation. A very marked difference was seen between different cell fractions in the extent of uptake and incorporation of label (relative to the concentration of cells in each fraction), and it was clear that most of the label was taken up by those cells that were not yet committed to meiosis.

This experiment was repeated using a different amino acid, L-phenylalanine, to see whether the effect was limited to arginine, and also using an earlier culture $(16 \mathrm{~h})$ under improved separation conditions. Again, most of the labelled precursor taken up during a 10 min pulse was found in those cells that had not yet begun to undergo meiosis or sporulation, or that were at any early stage in meiosis. 


\section{DISCUSSION}

The separation of sporulating cultures on Urografin gradients enables resolution of a single culture into fractions containing cells at certain physiological stages of meiosis or sporulation. For example, it was possible to obtain a fraction of cells that were committed to meiotic recombination but not yet committed to meiotic segregation. With care, and using shallow gradients, up to seven or eight fractions can be obtained. The correlation of these physiological stages with the morphology of ascospore formation is currently under study, but it is clear from the results presented here that as cells progress further into sporulation they band at positions of lower density in Urografin gradients. Moreover, they must undergo the transition from one state to the next in a fairly rapid manner. Since the separation method does not depend on density alone, the physiological basis for these changes is not obvious. The changes in lipid synthesis (Henry \& Halvorson, 1973) that accompany sporulation would lead to a decrease in cell density and could contribute to the effect; other processes which may be important include the breakdown of glycogen (Kane \& Roth, 1974) and the synthesis of the spore coat structures which may alter the density of the ascus and the permeability of parts of it. One of the main shifts in banding position of the cells seems to begin when the outline of developing ascospores can just be discerned by phase contrast microscopy, corresponding to the change from band 5 to band 6 in Fig. 2(a).

Several problems were encountered using this method. First, rather large amounts of Urografin were needed to separate relatively small samples, and unless the Urografin were to be recovered the technique could prove expensive if large amounts of material were needed for subsequent analysis. Other materials, including Ficoll and colloidal silica, were tried with no advantage over Urografin being apparent. Different strains of Saccharomyces cerevisiae also required preliminary characterization to establish the useful density range for the gradients. A problem that arose on several occasions, and for which no clear explanation has been found, was the flocculation or aggregation of cells in the Urografin. A number of variables were tested, including the use of various salts, buffers of different $\mathrm{pH}$, and lower sample loadings. None of these affected the aggregation markedly, although lowering the sample loading helped a little. In practice, the problem was remedied by recloning the yeast strain used. A note should also be made about the recovery of the bands from the centrifuge tubes after centrifugation. For the results presented here, fractions were obtained by pumping off the gradient from below via a peristaltic pump. It has recently been found that this leads to considerable broadening of the bands and better results can be achieved by avoiding pumps on the outlet side of the tube.

Despite the limitations, the technique has considerable potential for a number of biochemical studies of meiosis and sporulation in yeast since it enables resolution of cells at different physiological stages from a single culture.

This research was supported by grants from the Science Research Council and NATO (1148). F. V. was assisted by a grant from the Royal Society and N.A. was supported by the Government of Malaysia. We are grateful to Ian Hardie and Lynn Cuthbertson for technical assistance.

\section{REFERENCES}

Dawes, I. W., Mackinnon, D. A., Ball, D. E., Hardie, I. D., Sweet, D. M., Ross, F. M. \& MACDONALD, F. (1977). Identifying sites of simultaneous DNA replication in eukaryotes by $N$-methyl- $N^{\prime}$-nitro- $N$-nitrosoguanidine multiple mutagenesis. Molecular and General Genetics 152, 53-57.

Esposito, R. E. \& Esposito, M. S. (1974). Genetic recombination and commitment to meiosis in Saccharomyces. Proceedings of the National Academy of Sciences of the United States of America 71, 3172-3176.

Esposito, M. S., Esposito, R. E., Arnaud, M. \& Halvorson, H. O. (1970). Conditional mutants in meiosis in yeast. Journal of Bacteriology 100 , 180-186. 
FAST, D. (1973). Sporulation synchrony of Saccharomyces cerevisiae grown in various carbon sources. Journal of Bacteriology 116, 925-930.

HenRY, S. A. \& Halvorson, H. O. (1973). Lipid synthesis during sporulation of Saccharomyces cerevisiae. Journal of Bacteriology 114, 1158-1163.

KANE, S. M. \& Roth, R. (1974). Carbohydrate metabolism during ascospore development in yeast. Journal of Bacteriology 118, 8-14.

Magee, P. T. \& Hopper, A. K. (1974). Protein synthesis in relation to sporulation and meiosis in yeast. Journal of Bacteriology 119, 952-960.
Mills, D. (1972). Effect of $\mathrm{pH}$ on adenine and amino acid uptake during sporulation in Saccharomyces cerevisiae. Journal of Bacteriology 112, 519-526.

Roth, R. \& Halvorson, H. O. (1969). Sporulation of yeast harvested during logarithmic growth. Journal of Bacteriology 98, 831-832.

Sando, N., Maeda, M., Endo, T., OKa, R. \& Hayashibe, M. (1973). Induction of meiosis and sporulation in differently aged cells of Saccharomyces cerevisiae. Journal of General and Applied Microbiology 19, 359-373. 